\title{
SOLUTIONS TO FRACTIONAL DIFFERENTIAL EQUATIONS THAT EXTEND
}

\author{
Christopher C. TISDELL
}

Abstract. This note discusses the question: When do nonlinear fractional differential equations of arbitrary order have solutions that extend to a maximal interval of existence? We show that a growth condition on the right-hand side of the equation ensures that solutions will extend. The method uses a classical approach from analysis, namely the divergence of an infinite series. It is interesting to note that the growth condition is related to the order of the fractional differential equation involved. A YouTube video from the author that is designed to complement this research is available at http://tinyurl.com/Extend-FDE.

Mathematics subject classification (2010): 40A05, 34A08, 34A12.

Keywords and phrases: extension of solutions, existence of solutions, nonlinear fractional differential equations of arbitrary order, initial value problem, growth condition.

\section{REFERENCES}

[1] Michele Caputo, Linear models of dissipation whose $Q$ is almost frequency independent. II (English summary), Reprinted from Geophys. J. R. Astr. Soc. 13, 5 (1967), 529-539. Fract. Calc. Appl. Anal. 11, 1 (2008), 4-14.

[2] Kai Diethelm, Neville J. Ford, Analysis of fractional differential equations, J. Math. Anal. Appl. 265, 2 (2002), 229-248.

[3] KAi Diethelm, NeVille J. FORD, Multi-order fractional differential equations and their numerical solution, Appl. Math. Comput. 154 (2004), 621-540.

[4] KAI DiETHELM, The analysis of fractional differential equations, Springer, Heidelberg, 2010.

[5] Anatoly A. Kilbas, Hari M. Srivastava, JuAn J. Trujillo, Theory and applications of fractional differential equations, North-Holland Mathematics Studies, 204. Elsevier Science B.V., Amsterdam, 2006.

[6] V. Lakshmikantham, A. S. Vatsala, Theory of fractional differential inequalities and applications, Commun. Appl. Anal. 11, 3-4 (2007), 395-402.

[7] V. Lakshmikantham, A. S. VAtsala, General uniqueness and monotone iterative technique for fractional differential equations, Appl. Math. Lett. 21, 8 (2008), 828-834.

[8] V. Lakshmikantham, A. S. VATSAla, Basic theory of fractional differential equations, Nonlinear Anal. 69, 8 (2008), 2677-2682.

[9] IGor Podlubny, Fractional differential equations. An introduction to fractional derivatives, fractional differential equations, to methods of their solution and some of their applications, Mathematics in Science and Engineering, 198, Academic Press, Inc., San Diego, CA, 1999.

[10] C. C. TISDELL, On the application of sequential and fixed-point methods to fractional differential equations of arbitrary order, J. Integral Equ. Appl. 24, 2 (2012), 283-319.

[11] C. C. TISDELL, When do fractional differential equations have solutions on the half line that are bounded by the Mittag-Leffler function?, Fract. Calc. Appl. Anal. (to appear).

[12] C. C. Tisdell, Gronwall's inequality and fractional differential equations, Dr Chris Tisdell's YouTube Channel, 06/09/2011. Accessed 25/06/2014 www . youtube. com/watch?v=Ixags16MWxI.

[13] C. C. Tisdell, Approximate solutions to fractional differential equations, Dr Chris Tisdell's YouTube Channel, 08/09/2011. Accessed 25/06/2014 www. youtube.com/watch?v=d5tZ7M7c_Y4. 
[14] C. C. TISDELl, Banach fixed point thoerem and differential equations, Dr Chris Tisdell's YouTube Channel, 08/09/2011. Accessed 25/06/2014 www . youtube. com/watch?v=RhAjh8QpkDY.

[15] C. C. Tisdell, Applications of analysis to fractional differential equations, Dr Chris Tisdell's YouTube Channel, 22/03/2013. Accessed 25/06/2014 www. youtube. com/watch?v=zIc1_7iYBPk.

[16] AurEL Wintner, The non-local existence problem of ordinary differential equations, Amer. J. Math. 67 (1945), 277-284. 